\title{
Impacto da remoção de plântulas sobre a estrutura da comunidade regenerante de Floresta Estacional Semidecidual
}

\author{
Ricardo Augusto Gorne Viani ${ }^{1,3}$ e Ricardo Ribeiro Rodrigues ${ }^{2}$
}

Recebido em 24/09/2007. Aceito em 15/02/2008

\begin{abstract}
RESUMO - (Impacto da remoção de plântulas sobre a estrutura da comunidade regenerante de Floresta Estacional Semidecidual). O transplante de plântulas e indivíduos jovens de florestas naturais tem sido considerado como alternativa à produção de mudas de espécies nativas para a restauração florestal, sem que tenham sido realizados estudos sobre os possíveis impactos dessa prática sobre a comunidade vegetal regenerante. Nesse trabalho foram analisadas diferentes intensidades de retirada de plântulas e indivíduos jovens de até $30 \mathrm{~cm}$, de remanescente de Floresta Estacional Semidecidual, a fim de verificar o quanto essa operação pode comprometer a estabilidade da comunidade regenerante. Foram instaladas 80 parcelas de $2 \times 2 \mathrm{~m}$, distribuídas em dois ambientes (borda e interior da floresta) e em quatro tratamentos de retirada de regenerantes (I,II - $100 \%$ de retirada com ou sem revolvimento do solo, III - 50\% de retirada sem revolvimento do solo e IV - testemunha sem retirada de regenerantes). Avaliou-se a densidade e a riqueza da regeneração antes da execução dos tratamentos e após seis, 12 e 18 meses. Os resultados foram comparados entre tratamentos para cada período de avaliação e entre períodos de avaliação para cada tratamento. Foram constatadas semelhanças entre borda e interior. Não houve incremento da regeneração com revolvimento do solo. Parcelas submetidas à retirada dos regenerantes recuperaram em parte a densidade; porém apresentaram riqueza menor quando comparadas à testemunha e aos valores iniciais antes da execução dos tratamentos. A remoção das plântulas pode comprometer a regeneração de espécies que ocorrem em baixa densidade, o que sugere que a utilização da regeneração natural como fonte de mudas para a restauração florestal seja voltada para espécies abundantes e com estratégias de regeneração conhecidas e não para a comunidade como um todo.
\end{abstract}

Palavras-chave: ecologia florestal, plântulas, recuperação de áreas degradadas, regeneração natural, restauração ecológica

\begin{abstract}
Impact of seedling removal on regenerating community structure of a seasonal semideciduous forest). Transplanting seedlings and saplings from natural forests has been considered an alternative to producing saplings of native species for forest restoration purposes, but the possible impact of this procedure on plant community regeneration has not been investigated. This work evaluates the impact of different treatments of shrub and tree-seedling (up to $30 \mathrm{~cm}$ ) removal from a seasonal semideciduous forest fragment located in southeastern Brazil on the natural regeneration process. Eighty $2 \times 2 \mathrm{~m}$ plots were installed in two habitats (forest edge and interior) and submitted to four seedling-removal treatments (I, II - 100\% removal with or without soil mixing; III - 50\% removal without soil mixing; and IV - control treatment without seedling removal). Regeneration density and richness were evaluated before treatment as well as 6,12 and 18 months later. The results were compared among treatments for each evaluation period and among periods within treatments. There were similarities between edge and interior. The natural regeneration process did not improve with soil mixing. Plots submitted to seedling removal partially recovered plant density; however, these plots had lower species richness when compared to the control and to the initial values before treatment. Seedling removal has a negative impact on the regeneration process of low-density species, thus the use of natural regeneration as a sapling source for forest restoration purposes should focus only on highdensity species with well-known regeneration strategies and not on the community as a whole.
\end{abstract}

Key words: forest ecology, seedlings, restoration of degraded lands, natural regeneration, restoration ecology

\section{Introdução}

A obtenção de mudas de diversas espécies do ambiente regional em quantidade suficiente para o plantio é o primeiro e um dos principais pontos de estrangulamento dos programas de restauração ecológica (Fonseca et al. 2001; Santarelli 2004). A análise de 30 viveiros florestais do Estado de São Paulo revelou que cerca de
340 espécies arbóreas nativas são produzidas, no entanto, a maioria dos viveiros concentra sua produção em apenas 30 espécies, as quais são as prontamente disponíveis e com tecnologia de produção conhecida (Barbosa et al. 2003).

Em conseqüência disto, dados obtidos no monitoramento de áreas restauradas no Estado de São Paulo, Sudeste do Brasil, revelam que os plantios de

\footnotetext{
1 Universidade Estadual de Campinas, Instituto de Biologia, Departamento de Botânica, Programa de Pós-Graduação em Biologia Vegetal, C. Postal 6109, 13083-970 Campinas, SP, Brasil

2 Universidade de São Paulo, Escola Superior de Agricultura Luiz de Queiroz, Departamento de Ciências Biológicas, C. Postal 9, 13418-900 Piracicaba, SP, Brasil

3 Autor para correspondência: viani@unicamp.br
} 
1016 Viani \& Rodrigues: Impacto da remoção de plântulas sobre a estrutura da comunidade regenerante de Floresta...

restauração contam geralmente com apenas 35 espécies florestais, quase sempre as mesmas, independente das características ambientais do local restaurado e da flora regional, tendo como agravante o fato de dois terços destas pertencerem aos estágios iniciais da sucessão secundária (Barbosa et al. 2003). Desta forma, em alguns casos, a sustentabilidade das florestas restauradas em paisagens fragmentadas pode ficar comprometida, em função do baixo número de espécies utilizadas na implantação, principalmente de espécies finais da sucessão ecológica (Souza \& Batista 2004).

A limitação do número de espécies disponíveis nos viveiros de mudas florestais nativas é conseqüência, dentre outros fatores, das dificuldades para obtenção de sementes e da ausência de tecnologia para produção de mudas por sementes de muitas espécies nativas (Silva et al. 2003; Zamith \& Scarano 2004). A variabilidade interespecífica, a presença de diversificados mecanismos de dormência (Vázques-Yanes \& Orozco-Segovia 1993; Oliveira et al. 2003), os altos índices de predação (Zamith \& Scarano 2004) e o conhecimento limitado sobre a fenologia e a fisiologia de parte significativa das plantas tropicais são barreiras que dificultam a produção de mudas de espécies nativas a partir de sementes.

Visando contornar esses problemas e aumentar a diversidade da restauração ecológica, alguns trabalhos em regiões tropicais têm recomendado como técnica alternativa a transferência de plântulas e de indivíduos jovens regenerantes de áreas florestais remanescentes para viveiros ou diretamente para as áreas a serem restauradas (Auer \& Graça 1995; Djers et al. 1998; Nemer et al. 2002; Viani \& Rodrigues 2007). Essa técnica traria vantagens como a eliminação de etapas trabalhosas do processamento de sementes e a possibilidade de se produzir mudas de espécies com inconvenientes de dormência ou com baixa produção e/ou dificuldade de coleta de sementes (Viani \& Rodrigues 2007).

Entretanto, além de não prevista na legislação ambiental brasileira (não constam, por exemplo, no Código Florestal Brasileiro e no SNUC - Sistema Nacional de Unidades de Conservação), essa técnica ainda não foi avaliada cientificamente em relação aos impactos causados na comunidade vegetal regenerante. Nesse sentido, a efetiva recomendação deste procedimento como técnica de restauração ecológica depende da realização prévia de estudos específicos que avaliem os impactos da retirada de plântulas e indivíduos jovens das áreas naturais, de forma a evitar que se torne mais uma atividade degradadora das formações naturais (Viani et al. 2007).

Vários são os processos ecológicos que afetam a estrutura e a composição da comunidade de plântulas e indivíduos jovens. Esses processos podem ter efeitos significativos na regeneração arbórea de florestas tropicais (Clark \& Clark 1985), uma vez que a sobrevivência no período inicial de vida de uma planta garante a manutenção da população de uma espécie e afeta não só a sua abundância e distribuição, mas toda a composição e estrutura da comunidade (Denslow 1991).

Na comunidade vegetal, a regeneração natural é determinada pela junção das probabilidades de chegada e sobrevivência no mosaico florestal. A probabilidade de sobrevivência depende dos atributos fisiológicos da espécie, das características do ambiente e das interações das espécies entre si, já a probabilidade de chegada é determinada pela dispersão das sementes e propágulos (Schupp et al. 1989; Melo et al. 2004). Nesse sentido, o restabelecimento das comunidades regenerantes após distúrbios e/ou intervenções antrópicas é dependente da disponibilidade de sementes oriundas da dispersão ou do banco de sementes do solo (Grombone-Guaratini \& Rodrigues 2002).

O recrutamento de plântulas é variável no tempo, em decorrência da variação anual na produção e na fenologia de dispersão das sementes (De Steven 1994), em função da reprodução supra-anual de algumas espécies arbóreas tropicais (Lieberman 1996) e devido à ocorrência de chuvas, que mesmo em baixas intensidades, aumentam a emergência de plântulas (Santos \& Válio 2002).

A luz também exerce influência no processo de regeneração natural da floresta (Whitmore 1989). Borda e interior florestal são ambientes distintos em vários aspectos abióticos, incluindo a intensidade de luz que os atinge (Murcia 1995), consequentemente são distintos também em relação ao recrutamento de árvores e arbustos (Laurance et al. 1998). Na borda florestal, em áreas declivosas ou em áreas com histórico acentuado de degradação, a alta intensidade de luz incidente propicia a germinação de espécies pioneiras, que crescem somente em ambientes abertos, sendo intolerantes à sombra e não encontradas sob o dossel florestal (Swaine \& Whitmore 1988; Lieberman 1996). Por outro lado, no interior da floresta, a menor intensidade de luz incidente leva a formação do banco de plântulas por espécies não pioneiras, que germinam sob o dossel e cujas plântulas podem se estabelecer e permanecer sob a sombra da floresta por muitos anos, até que os recursos limitantes se tornem disponíveis (Swaine \& Whitmore 1988; Lieberman 1996). Em áreas abertas e bem iluminadas comuns na borda dos remanescentes florestais (Murcia 1995), o recrutamento pode ser afetado também pelo revolvimento superficial do solo, que desencadeia o processo de regeneração natural das espécies pioneiras constituintes do banco de sementes (Kwit et al. 2000; Rozza et al. 2007). 
Nesse contexto, este estudo teve como objetivo verificar se a remoção de plântulas e indivíduos jovens regenerantes arbustivos e arbóreos causa impacto na dinâmica da comunidade regenerante, e se a intensidade desse impacto é afetada pela distância da borda da floresta, pela intensidade de remoção de plantas e pelo revolvimento do solo posterior a remoção. Pressupõe-se que a capacidade da comunidade em regeneração repor as perdas de densidade e riqueza decorrentes da extração de plântulas é maior quanto menor a intensidade de extração de plântulas e, ao menos na borda florestal, também maior quando seguida de revolvimento superficial do solo (indutor da regeneração natural).

\section{Material e métodos}

Área de estudo - O estudo foi realizado na Fazenda Santa Terezinha $\left(23^{\circ} 02^{\prime}-23^{\circ} 03^{\prime} \mathrm{S}, 48^{\circ} 11^{\prime}-48^{\circ} 12^{\prime} \mathrm{W}\right)$, município de Bofete-SP, sudeste do Brasil. A Fazenda Santa Terezinha tem área de 3.900 ha, sendo cerca de 2.300 ha destinados ao cultivo de Eucalyptus spp. e 650 ha ocupados com fragmentos de vegetação nativa, em diferentes estádios de conservação.

A altitude média é de $600 \mathrm{~m}$ e o clima regional é do tipo $C f a$, segundo a classificação de Köppen, com a temperatura média do mês mais quente superior a $22^{\circ} \mathrm{C}$ e a do mês mais frio inferior a $18^{\circ} \mathrm{C}$. A precipitação anual é de aproximadamente 1.440 mm (SIGRH 2007).

A vegetação regional dominante é a Floresta Estacional Semidecidual, caracterizada pelo fato de 20-50\% das árvores do dossel florestal perderem as folhas na estação mais seca (Veloso 1992). A vegetação nativa da região, assim como de toda a área ocupada com Floresta Estacional Semidecidual, encontra-se altamente fragmentada e restrita a manchas pequenas e isoladas (Dinerstein et al. 1995; Di Bitetti et al. 2003).

Todo o estudo foi conduzido num único fragmento florestal remanescente, de aproximadamente 150 ha, que contém desde áreas de interflúvio até locais de floresta ribeirinha, com influência fluvial quase permanente.

Delineamento experimental - O remanescente florestal foi estratificado em borda e interior, sendo considerada borda a faixa de floresta contida a até $35 \mathrm{~m}$ do limite da floresta. Posteriormente, dentro de cada ambiente (borda e interior), foram instalados 10 blocos com quatro parcelas de $2 \times 2 \mathrm{~m}$ cada. Cada parcela do bloco foi submetida a um tratamento distinto, determinado de forma aleatória. Os quatro tratamentos testados foram: I - retirada de todos os regenerantes da parcela, com posterior revolvimento superficial do solo (profundidade de $5 \mathrm{~cm}$ ); II - retirada de todos os regenerantes da parcela sem posterior revolvimento superficial do solo; III - retirada de 50\% dos regenerantes da parcela, de forma aleatória, sem posterior revolvimento superficial do solo; IV - testemunha, sem a retirada de regenerantes da parcela e sem revolvimento do solo.

As intensidades de retirada de regenerantes foram escolhidas visando abranger tratamentos extremos com retirada total dos regenerantes (I e II) e um tratamento com retirada parcial (III), sob a hipótese que a retirada parcial poderia minimizar os impactos sobre a comunidade. Foi considerado também um tratamento testemunha (IV), representando a regeneração da floresta em condições naturais. Uma vez que o revolvimento do solo pode ativar o banco de sementes (Putz 1983; Kwit et al. 2000) foi adotado no tratamento I, além da retirada total dos regenerantes, o revolvimento posterior do solo, sob a hipótese que essa prática poderia induzir o restabelecimento do estrato regenerante.

Obtenção dos dados - Foram considerados regenerantes os indivíduos pertencentes a espécies arbustivas ou arbóreas, com altura até $30 \mathrm{~cm}$. Foi realizada uma avaliação prévia (tempo 0) anterior à aplicação dos tratamentos, em maio/2003. Imediatamente após a avaliação inicial, os tratamentos foram executados em cada parcela, conforme delineamento prévio. Seguindo os mesmos procedimentos, foram realizadas avaliações aos seis (novembro/2003), 12 (maio/2004) e 18 meses (novembro/2004).

Análise dos dados - Para cada tratamento, nos quatro períodos de avaliação ( $0,6,12$ e 18 meses), foi obtido, de forma separada para os dois ambientes (borda e interior do remanescente florestal), o número total de espécies.

Com base nos números médios de indivíduos e de espécies por parcela, registrados nas avaliações aos seis, 12 e 18 meses em cada tratamento, procedeu-se análise de covariância conjunta (Pimentel-Gomes \& Garcia 2002), sendo os dados do tempo 0 (avaliação inicial, antes da execução dos tratamentos) a covariável. Para o enquadramento dos dados dentro das suposições da estatística paramétrica e da análise de variância, os valores originais foram transformados segundo o método Box Cox (Box et al. 1978), conforme demonstrado a seguir:

Número de indivíduos aos seis meses $=\left(\mathrm{n}^{\circ}\right.$ de indivíduos aos seis meses $+0,5)^{0,3}$

Número de indivíduos aos 12 meses $=\left(\mathrm{n}^{\circ} \mathrm{de}\right.$ indivíduos aos 12 meses $+0,5)^{0,2}$

Número de indivíduos aos 18 meses $=\left(\mathrm{n}^{\circ} \mathrm{de}\right.$ indivíduos aos 18 meses $+0,5)^{0,2}$

Número de espécies aos seis meses $=\left(\mathrm{n}^{\circ}\right.$ de espécies aos seis meses $+0,5)^{0,5}$

Número de espécies aos 12 meses $=\left(\mathrm{n}^{\circ}\right.$ de espécies aos 12 meses $+0,5)^{0,5}$

Número de espécies aos 18 meses $=\left(\mathrm{n}^{\circ}\right.$ de espécies aos 18 meses $+0,5)^{0,5}$ 
1018 Viani \& Rodrigues: Impacto da remoção de plântulas sobre a estrutura da comunidade regenerante de Floresta...

Quando os resultados da análise conjunta demonstraram interação significativa entre os ambientes (borda e interior do remanescente florestal) e os tratamentos, as médias dos tratamentos foram comparadas separadamente em cada área. No entanto, quando isto não ocorreu, sendo apenas significativos os tratamentos, estes foram comparados sem a separação entre borda e interior. Para tanto, em ambos os casos, utilizou-se o teste de comparação múltipla de TukeyKramer (nível de significância de 5\%) (Pimentel-Gomes \& Garcia 2002).

Dentro de cada tratamento, foram feitas comparações das médias de número de indivíduos e de espécies do tempo 0 com os demais períodos de avaliação (seis, 12 e 18 meses). Para tanto, procedeu-se a comparação das médias para dados pareados, por meio do (1) teste " $t$ " de Student, quando os dados apresentavam normalidade, (2) teste de Wilcoxon para dados pareados (Ordem Assinaladas), quando os dados não eram normais, mas apresentavam simetria, e (3) teste do Sinal, quando os dados não eram nem normais e nem simétricos, conforme descrito por Campos (1983) e considerando sempre o nível de significância de $5 \%$.

\section{Resultados e discussão}

Variações entre os tratamentos - Para a densidade de plântulas, apenas aos 18 meses houve interação entre os ambientes (borda e interior do remanescente florestal) e os tratamentos $(F=3,51 ; \mathrm{GL}=3, \mathrm{P}=0,0214)$. Nos demais períodos de avaliação (seis e 12 meses) não ocorreu interação do ambiente (borda e interior do remanescente florestal) com os tratamentos (aos seis meses $F=1,13 ; \mathrm{GL}=3 ; \mathrm{P}=0,3470$ e aos 12 meses $F=2,05 ; \mathrm{GL}=3 ; \mathrm{P}=0,1180$ ), e por isso, os dados de densidade média de regeneração foram analisados conjuntamente. Em relação ao número médio de espécies por parcela, em nenhum período de avaliação houve interação entre os ambientes (borda e interior do remanescente florestal) e os tratamentos (aos seis meses $F=1,79 ; \mathrm{GL}=3 ; \mathrm{P}=0,1610$; aos 12 meses $F=0,20$; $\mathrm{GL}=3 ; \mathrm{P}=0,8951$ e aos 18 meses $F=1,21 ; \mathrm{GL}=3$; $\mathrm{P}=0,3137$ ), sendo para essa variável os dados analisados sempre conjuntamente.

A não ocorrência, na maioria das análises efetuadas nesse estudo, de diferenças dentro dos tratamentos em função das parcelas estarem na borda ou no interior do remanescente florestal indica que os ambientes de borda e interior considerados nesse estudo, possivelmente não sejam dissimilares para os fatores que interferem diretamente na densidade e riqueza de espécies regenerantes. Deve-se destacar, no entanto, que a borda foi delimitada apenas segundo o critério de distância do exterior, sem considerar aspectos biológicos e ambientais (por exemplo, incidência da radiação solar) e sem considerar aspectos que influenciam diretamente a extensão dos efeitos de borda, como a forma, o tamanho e o grau de degradação do fragmento (Laurance et al. 2002). Em alguns casos, os efeitos de borda se estendem para mais de $100 \mathrm{~m}$ do interior de remanescentes florestais (Murcia 1995; Laurance et al. 2002). Se assim ocorrer na área de estudo, as parcelas locadas no interior florestal podem estar na verdade sob condição de borda, sendo, portanto similares em relação às parcelas locadas na borda. Uma outra justificativa para a ausência de diferenças entre os dois ambientes avaliados nesse estudo pode se referir ao fato do entorno do remanescente ser todo ocupado por plantios de Eucalpytus spp. Plantios florestais são ambientes com sombreamento elevado quando comparados a áreas abertas e esse sombreamento pode minimizar os efeitos de borda sobre o remanescente florestal (Murcia 1995).

Aos seis meses, os tratamentos III (retirada de 50\% dos indivíduos regenerantes) e IV (testemunha, sem retirada dos regenerantes) apresentaram número médio de indivíduos por parcela significativamente superiores aos tratamentos I e II (ambos com retirada total dos regenerantes) (Fig. 1). Esse fato é compreensível, uma vez que os tratamentos I e II tiveram $100 \%$ de retirada dos regenerantes e que a maior parte dos seis meses seguintes a remoção (junho até novembro, fim do outono até fim da primavera), embora abranja a época com pico de produção de frutos na formação florestal estudada (Morellato 1995; Carmo \& Morellato 2004), corresponde ao período do ano tido como menos chuvoso e conseqüentemente menos favorável à germinação e ao recrutamento dos indivíduos arbustivos e arbóreos nas florestas tropicais (Grombone-Guaratini \& Rodrigues 2002; Santos \& Válio 2002).

Entretanto, ainda aos seis meses, não houve diferença na densidade média de indivíduos por parcela do tratamento IV (sem retirada de plântulas) em relação ao tratamento III (50\% de retirada das plântulas) (Fig. 1), indicando que, em apenas seis meses, as parcelas submetidas a este tratamento já tinham, de certa forma, recuperado o número de indivíduos. Esse aspecto demonstra também que, ao menos para esse período (seis meses), o impacto sobre a comunidade regenerante é menor quanto menor a intensidade de remoção das plantas.

Aos 12 meses, assim como aos 18 meses para o interior do remanescente florestal, não foram observadas diferenças significativas no número médio de indivíduos por parcela entre os tratamentos. Aos 18 meses, para a borda do remanescente florestal, apenas o tratamento II apresenta número de indivíduos por parcela significativa- 
mente inferior ao tratamento IV (testemunha) (Fig. 1). Esses dados apontam capacidade de auto-recuperação (resiliência) no tempo das parcelas submetidas ao retirada de plântulas. Porém, é importante destacar que no tratamento IV (testemunha, sem retirada dos regenerantes), houve redução do número médio de indivíduos após a avaliação inicial, principalmente em função da redução na densidade de Protium spruceanum (Benth.) Engl., que correspondia a mais da metade dos indivíduos desse tratamento na avaliação inicial. Esse aspecto dificulta em parte a interpretação dos efeitos dos tratamentos, uma vez que a mortalidade de grande parte dos indivíduos de Protium spruceanum do tratamento testemunha, compensa a diminuição da densidade de regenerantes decorrente da retirada das plântulas e indivíduos jovens nos demais tratamentos (I-III).

Aos 12 meses, o tratamento IV (testemunha) apresentou número médio de espécies por parcela significativamente maior que os demais tratamentos. Aos seis e 18 meses o tratamento IV apresentou média de espécies por parcela significativamente superior aos
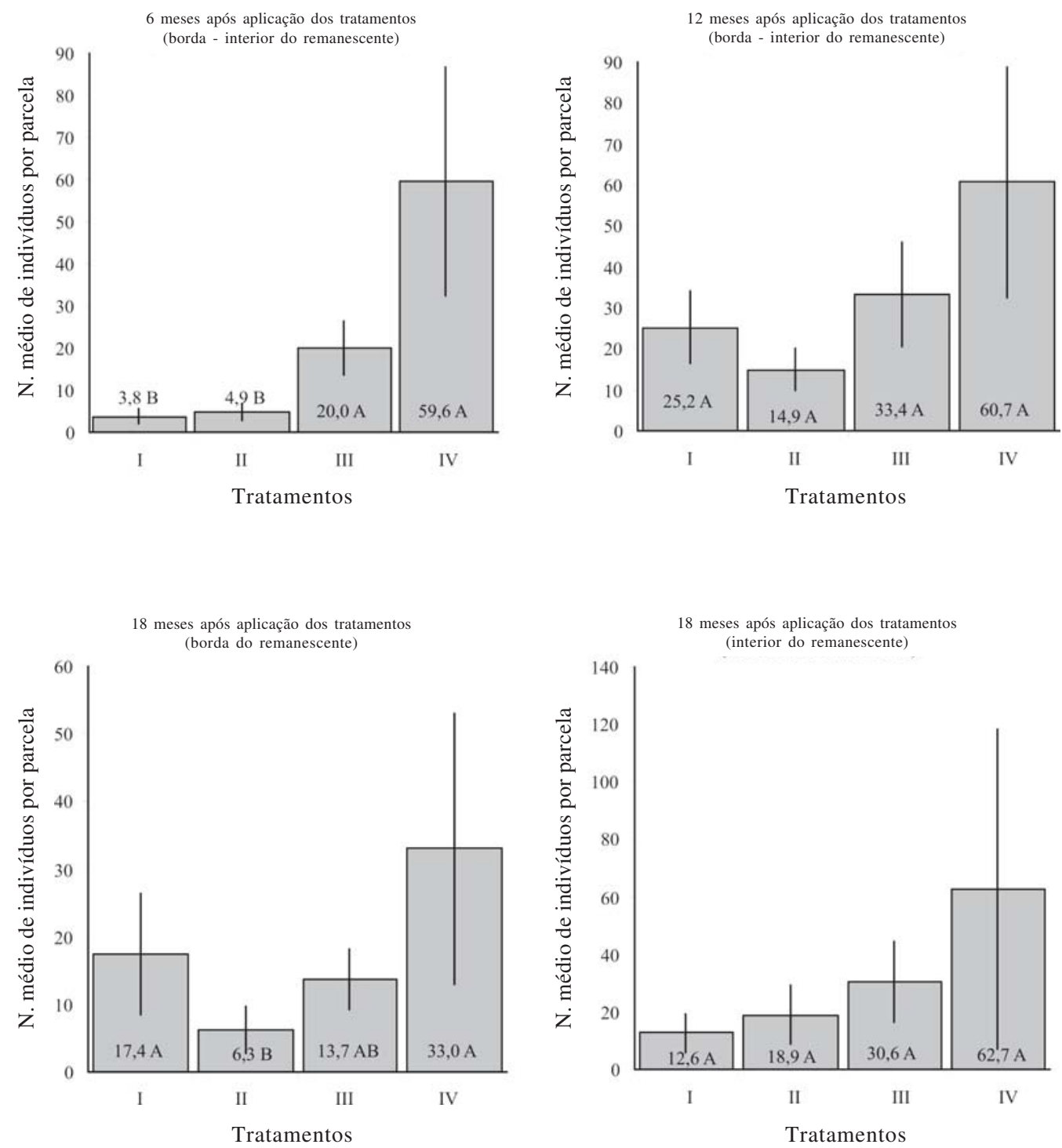

Figura 1. Resultados da comparação do número médio de plântulas arbustivas ou arbóreas por parcela $(2 \times 2 \mathrm{~m})$ entre os tratamentos, nos períodos de avaliação de seis, 12 e 18 meses, por meio da análise de variância com covariável (número de indivíduos no período inicial tempo 0). Tratamento I: $100 \%$ de retirada das plântulas com revolvimento posterior do solo; II: $100 \%$ de retirada das plântulas sem revolvimento posterior do solo; III: $50 \%$ de retirada das plântulas sem revolvimento posterior do solo e IV: testemunha sem retirada das plântulas. Remanescente de Floresta Estacional Semidecidual, Fazenda Santa Terezinha, Bofete, SP, Brasil. Barras com letras diferentes diferem entre si $(\mathrm{P}<0,05)$. Linhas verticais em preto correspondem ao intervalo de confiança $(95 \%)$. 
tratamentos I e II, porém não diferiu do tratamento III. Já o tratamento III apresentou uma média de espécies por parcela significativamente maior que o tratamento I aos seis meses e que o tratamento II aos 12 meses (Fig. 2). Esses dados sugerem novamente que em determinadas situações uma menor intensidade de remoção pode causar menores impactos na comunidade regenerante.

Analisando-se apenas os resultados dos tratamentos I (com revolvimento superficial do solo após a retirada das plântulas) e II (sem revolvimento superficial do solo), observa-se que ambos não diferiram até os 12 meses após a aplicação dos tratamentos para o número médio de indivíduos por parcela. Aos 18 meses após a aplicação dos tratamentos, essa variável diferiu significativamente apenas na borda do remanescente florestal, sendo maior no tratamento I (Fig. 1). Em relação ao número médio de espécies por parcela, os tratamentos I e II não diferiram entre si, em nenhum dos períodos de avaliação (Fig. 2).

Considera-se, portanto, que na escala de tempo de observação e nas condições específicas deste estudo, o revolvimento superficial do solo não se comportou como um indutor da regeneração natural, contrariando as observações de Nunez-Farfan \& Dirzo (1988) e Kwit et al. (2000) e as hipóteses iniciais estabelecidas nesse estudo. Possivelmente isso se justifique pela época em que foi realizado o revolvimento (mês de maio). Esse período coincide com um período pouco chuvoso, não favorável à germinação das plântulas (GromboneGuaratini \& Rodrigues 2002; Santos \& Válio 2002). Outro aspecto refere-se à luminosidade, que mesmo na borda do remanescente florestal pode ser baixa, decorrente do entorno do remanescente florestal ocupado com plantios de Eucalyptus spp., não estimulando a germinação das espécies iniciais da sucessão ecológica, que estariam no banco de sementes e seriam induzidas a regenerar a partir do revolvimento do solo (Putz 1983).

Variações temporais na comunidade regenerante - Com exceção do tratamento IV (testemunha) aos seis e 12 meses e do tratamento I aos 12 e 18 meses, ambos na borda do remanescente florestal, os demais tratamentos apresentaram redução no número de indivíduos das avaliações aos seis, 12 e 18 meses em relação à avaliação inicial (Fig. 3).

No tratamento IV (sem retirada de regenerantes), o número de espécies na avaliação inicial foi sempre igual ou inferior ao número de espécies nas avaliações seguintes (Tab. 1). Já nos tratamentos com remoção de plântulas (I - III) houve redução considerável do número total de espécies nas avaliações aos seis, 12 e 18 meses em relação à avaliação inicial, realizada antes da aplicação dos tratamentos, sendo o menor número de espécies
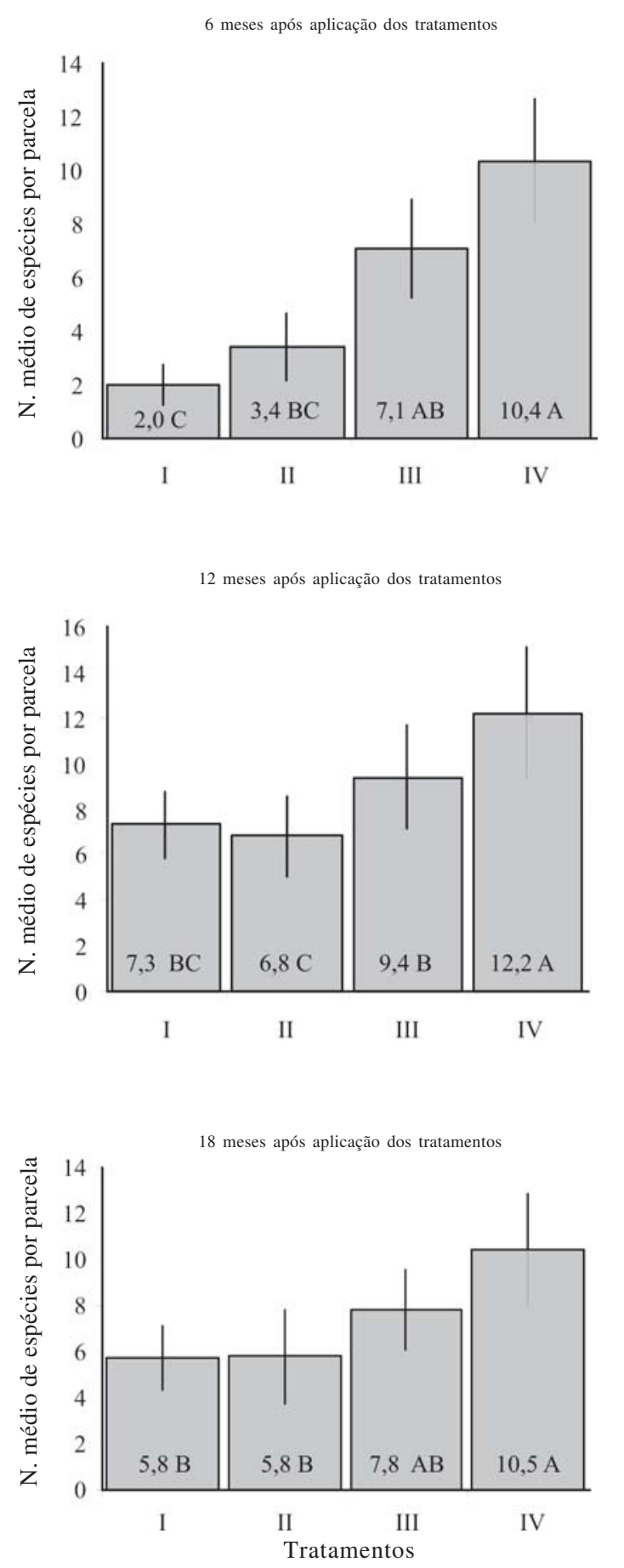

Figura 2. Resultados da comparação do número médio de espécies arbustivas ou arbóreas por parcela $(2 \times 2 \mathrm{~m})$ entre os tratamentos, nos períodos de avaliação de 6, 12 e 18 meses, por meio da análise de variância com covariável (número de espécies no período inicial tempo 0). Tratamento I: $100 \%$ de retirada das plântulas com revolvimento posterior do solo; II: $100 \%$ de retirada das plântulas sem revolvimento posterior do solo; III: $50 \%$ de retirada das plântulas sem revolvimento posterior do solo e IV: testemunha sem retirada das plântulas. Remanescente de Floresta Estacional Semidecidual, Fazenda Santa Terezinha, Bofete, SP, Brasil. Barras com letras diferentes diferem entre si $(\mathrm{P}<0,05)$. Linhas verticais em preto correspondem ao intervalo de confiança (95\%). 

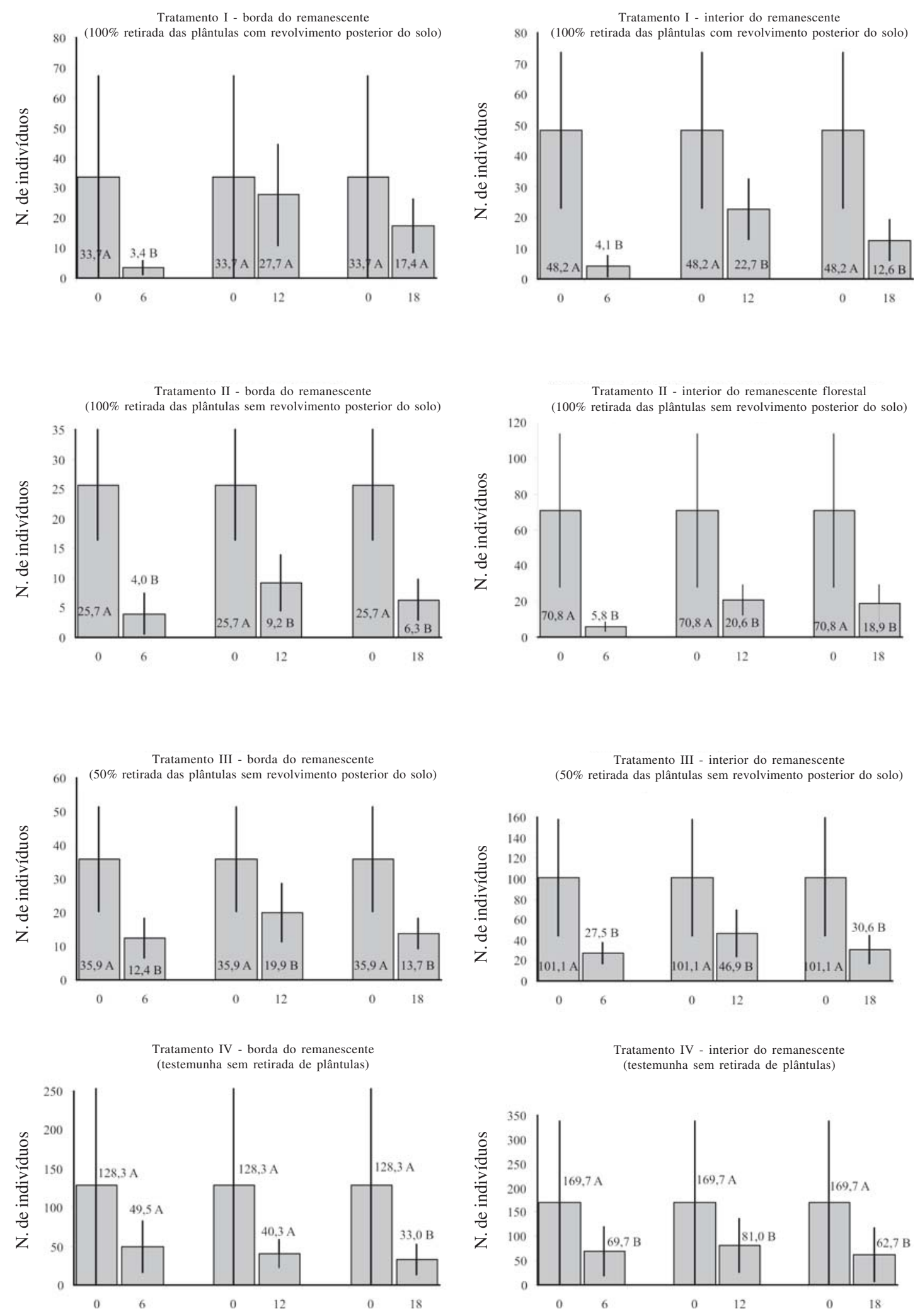

Tempo (em meses) após a retirada das plântulas

Tempo (em meses) após a retirada das plântulas

Figura 3. Comparação do número médio de plântulas arbustivas ou arbóreas por parcela ( $2 \times 2$ m), na avaliação prévia (tempo 0$)$ e aos 6 , 12 e 18 meses após a aplicação dos tratamentos. Barras com letras diferentes, diferem entre si $(\mathrm{P}<0,05)$. Linhas verticais em preto correspondem ao intervalo de confiança (95\%). Remanescente de Floresta Estacional Semidecidual, Fazenda Santa Terezinha, Bofete, SP, Brasil. 
1022 Viani \& Rodrigues: Impacto da remoção de plântulas sobre a estrutura da comunidade regenerante de Floresta...

encontrado sempre aos seis meses. Essa redução foi maior nos tratamentos I e II (retirada total dos indivíduos regenerantes) e menor no tratamento III (retirada de 50\% dos indivíduos de cada parcela) (Tab. 1), indicando que quanto maior a intensidade de remoção de plântulas, maior o impacto sobre a riqueza da comunidade regenerante.

O número de espécies amostradas apenas na avaliação inicial, antes da aplicação dos tratamentos, foi maior nos tratamentos com remoção de plântulas (I-III) do que para o tratamento testemunha (IV) (Tab. 1), indicando que nesses tratamentos (I-III), um maior número de espécies deixou de constituir a comunidade regenerante na área amostral, provavelmente em decorrência da remoção dos regenerantes (efeitos dos tratamentos). Esse aspecto demonstra que o impacto da retirada das plântulas contidas no banco pode ser significativo para algumas espécies, principalmente para as que apresentam baixa densidade de regeneração. A ocorrência de espécies arbustivas e arbóreas em densidades muito baixas é um comportamento comum para as florestas tropicais, mesmo quando os indivíduos estão na fase de plântulas (Hubbell et al. 1999). Possivelmente para estas espécies, tidas como raras, a retirada das plântulas comprometa a regeneração e a dinâmica da população. Este fato pode ser ainda agravado, caso, além da baixa densidade, a espécie apresente reprodução supra-anual, com recrutamento esporádico ou em longos intervalos de tempo (De Steven 1994; Lieberman 1996).

Tabela 1. Riqueza da comunidade de plântulas de cada tratamento, nos diferentes períodos de avaliação das parcelas, Fazenda Santa Terezinha, Bofete, SP, Brasil. T0: tempo 0, anterior a aplicação dos tratamentos; T6, T12 e T18: respectivamente seis, 12 e 18 meses após a aplicação dos tratamentos; N. spp.: número total de espécies; \% redução: percentagem de redução do número de espécies em relação a avaliação inicial e N. spp. exclusivas: número de espécies exclusivas ao período de avaliação, considerando o total de espécies do tratamento.

\begin{tabular}{|c|c|c|c|c|c|}
\hline Área & Tratamento & Avaliação & N. spp. & \% redução & $\begin{array}{l}\text { N. spp. } \\
\text { exclusivas }\end{array}$ \\
\hline \multirow[t]{16}{*}{ Borda } & I & T0 & 49 & - & 18 \\
\hline & ( $100 \%$ de retirada das plântulas com revolvimento posterior do solo) & T6 & 14 & 71,4 & 1 \\
\hline & & $\mathrm{T} 12$ & 37 & 24,5 & 5 \\
\hline & & T18 & 30 & 38,8 & 2 \\
\hline & II & T0 & 48 & - & 16 \\
\hline & (100\% de retirada das plântulas sem revolvimento posterior do solo) & T6 & 16 & 66,7 & 2 \\
\hline & & $\mathrm{T} 12$ & 31 & 35,4 & 4 \\
\hline & & $\mathrm{T} 18$ & 34 & 29,2 & 6 \\
\hline & III & T0 & 38 & - & 11 \\
\hline & ( $50 \%$ de retirada das plântulas sem revolvimento posterior do solo) & T6 & 27 & 28,9 & 4 \\
\hline & & $\mathrm{T} 12$ & 34 & 10,5 & 5 \\
\hline & & T 18 & 31 & 18,4 & 4 \\
\hline & IV & T0 & 48 & - & 2 \\
\hline & (testemunha - sem retirada das plântulas) & T6 & 48 & 0,0 & 1 \\
\hline & & $\mathrm{T} 12$ & 52 & $-8,3$ & 4 \\
\hline & & T18 & 53 & $-10,4$ & 6 \\
\hline \multirow[t]{16}{*}{ Interior } & I & T0 & 60 & - & 23 \\
\hline & ( $100 \%$ de retirada das plântulas com revolvimento posterior do solo) & T6 & 12 & 80,0 & 0 \\
\hline & & $\mathrm{T} 12$ & 45 & 25,0 & 10 \\
\hline & & T18 & 40 & 33,3 & 7 \\
\hline & II & T0 & 64 & - & 17 \\
\hline & ( $100 \%$ de retirada das plântulas sem revolvimento posterior do solo) & T6 & 23 & 64,1 & 2 \\
\hline & & $\mathrm{T} 12$ & 47 & 26,6 & 9 \\
\hline & & $\mathrm{T} 18$ & 42 & 34,4 & 4 \\
\hline & III & T0 & 72 & - & 16 \\
\hline & ( $50 \%$ de retirada das plântulas sem revolvimento posterior do solo) & T6 & 47 & 34,7 & 1 \\
\hline & & $\mathrm{T} 12$ & 58 & 19,4 & 4 \\
\hline & & T18 & 52 & 27,8 & 1 \\
\hline & IV & T0 & 57 & - & 4 \\
\hline & (testemunha - sem retirada das plântulas) & T6 & 57 & 0,0 & 5 \\
\hline & & $\mathrm{T} 12$ & 68 & $-19,3$ & 8 \\
\hline & & T18 & 60 & $-5,3$ & 6 \\
\hline
\end{tabular}


Protium spruceanum foi a única espécie presente em todos os períodos de avaliação de todos os tratamentos, porém mesmo no tratamento IV (testemunha, sem remoção de plantas) apresentou grande redução no número de indivíduos. Essa redução do número de indivíduos ao longo do tempo sugere a ocorrência de um raleamento intra-específico de sua população, quer pela atuação de fatores bióticos, abióticos ou ambos em conjunto. Além disso, esses dados demonstram que a geração de novos indivíduos dessa espécie não foi igual durante o período de avaliação. É provável, portanto, que à espécie apresente reprodução supra-anual, com geração de coortes numerosas em intervalos de tempo superiores a um ano (De Steven 1994; Lieberman 1996) e que a avaliação inicial realizada nesse estudo tenha coincidido com um desses anos de geração de coortes numerosas.

Com exceção do tratamento I (100\% de retirada das plântulas, com revolvimento do solo) no interior do remanescente florestal, todos os demais tratamentos apresentaram espécies exclusivas em todos os períodos de avaliação. A presença de espécies exclusivas em quase todos os períodos de avaliação indica que algumas espécies permanecem por pouco tempo na comunidade de plântulas, ou por mortalidade dos indivíduos regenerantes, ou porque esses indivíduos passam à classe de altura superior. É possível ainda que alguns indivíduos e espécies possam ter composto a comunidade de plântulas temporariamente, somente durante o período entre duas avaliações (período inferior a seis meses), não tendo sido, portanto amostrados nas avaliações semestrais.

O fato de algumas espécies só apareceram temporariamente na comunidade de regenerantes indica que a retirada de plântulas visando à obtenção de mudas para a restauração ecológica em várias épocas do ano permitiria a obtenção de um número maior de espécies. Entretanto, a recuperação gradual no tempo da comunidade de plântulas e indivíduos jovens após a sua retirada indica que a dimensão do impacto sobre a dinâmica da floresta depende da freqüência com que a remoção dos regenerantes é realizada numa mesma área. Intervalos muito curtos de retirada de plântulas e indivíduos jovens num mesmo local proporcionariam tempo insuficiente para a auto-recuperação da comunidade de plântulas e indivíduos jovens, intensificando o impacto sobre a dinâmica de regeneração e manutenção da diversidade da floresta.

O tratamento IV, não apresentou, em nenhuma situação, diferença significativa no número médio de espécies por parcela da avaliação inicial em relação às demais avaliações (Fig. 4). Já os tratamentos I e II apresentaram número médio de espécies por parcela no tempo 0 significativamente superior aos valores das avaliações posteriores (Fig. 4), demonstrando que ambos os tratamentos, até os 18 meses, ainda não haviam recuperado os valores iniciais médios de riqueza por parcela. Isto se repetiu para o tratamento III, com exceção do período de 12 meses (Fig. 4), indicando que a retirada de apenas parte dos regenerantes (tratamento III - retirada de $50 \%$ dos indivíduos) pode ser menos impactante sobre o número médio de espécies por parcela.

Considerações finais e perspectivas futuras - As parcelas submetidas aos tratamentos que envolveram a retirada de plântulas, principalmente as do tratamento III (retirada de $50 \%$ dos regenerantes), estão recompondo a riqueza (número médio de espécies por parcela e riqueza total por tratamento). Em relação à densidade de regenerantes, em alguns casos, no curto período de avaliação, o número médio de indivíduos por parcela nas áreas submetidas à retirada de plântulas é semelhante aos níveis iniciais (tempo 0, antes da aplicação dos tratamentos) e não difere mais dos níveis do tratamento testemunha. Ressalta-se, no entanto, que mesmo diante desses resultados, populações de espécies com menor densidade de regeneração e de espécies raras localmente foram removidas da área experimental, mostrando o efeito negativo da retirada de plântulas sobre as populações dessas espécies.

A heterogeneidade espacial e temporal em relação à riqueza e à densidade é uma das características da comunidade de plântulas e indivíduos jovens (Hubbell et al. 1999; Oliveira et al. 2001; Viani et al. 2007). Esse aspecto por si só, retrata a dificuldade de compreensão do real impacto que a retirada da comunidade de regenerantes causa sobre a dinâmica florestal e de certa forma justifica a não recomendação a princípio, da retirada da comunidade de plântulas e indivíduos jovens como um todo, em áreas naturais remanescentes. No caso desse estudo, por exemplo, uma espécie (Protium spruceanum) se destacou das demais, apresentando um recrutamento maciço em um dos tratamentos, o que sugere que mesmo para o remanescente florestal em questão, é possível que os resultados não se repitam caso os tratamentos sejam executados novamente.

São necessários novos estudos sobre o tema, estudos que acompanhem individualmente cada plântula, monitorem as áreas submetidas à retirada dos regenerantes por períodos maiores e executem as operações de retirada dos regenerantes em vários locais e épocas do ano. Além disso, embora a heterogeneidade espacial e temporal da comunidade de plântulas seja natural, recomenda-se que estudos futuros busquem novas formas de amostragem, de modo a diminuir a influência dessa heterogeneidade na comparação de áreas 
1024 Viani \& Rodrigues: Impacto da remoção de plântulas sobre a estrutura da comunidade regenerante de Floresta...

Tratamento I - borda do remanescente

(100\% retirada das plântulas com revolvimento posterior do solo)

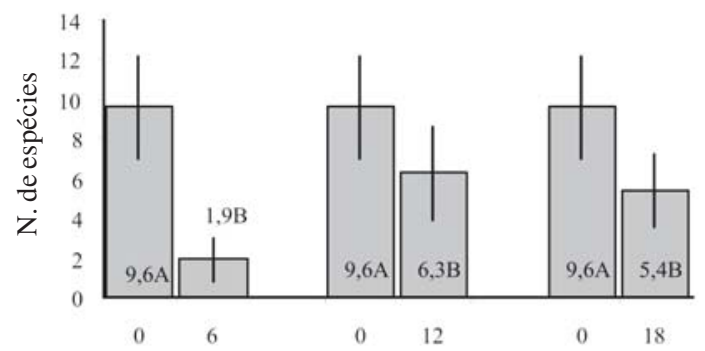

Tratamento II - borda do remanescente

(100\% retirada das plântulas sem revolvimento posterior do solo)

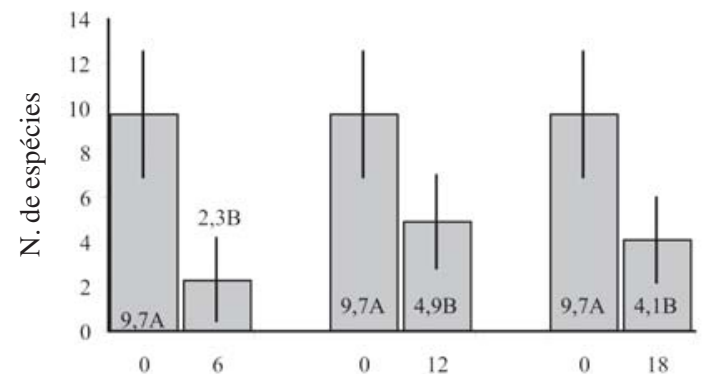

Tratamento III - borda do remanescente (50\% retirada das plântulas sem revolvimento posterior do solo)
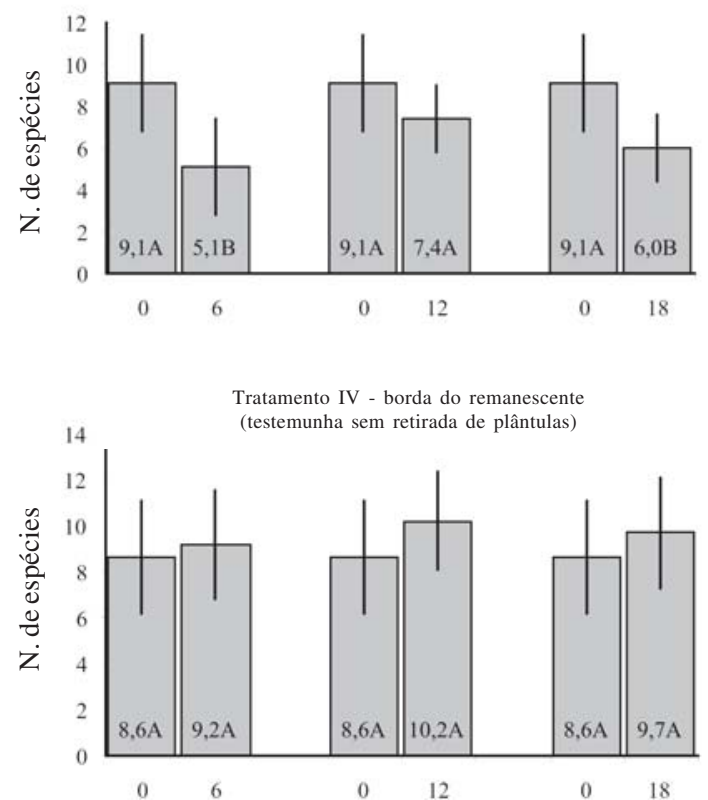

Tempo (em meses) após a retirada das plântulas
(100\% retirada das plântulas com revolvimento posterior do solo)

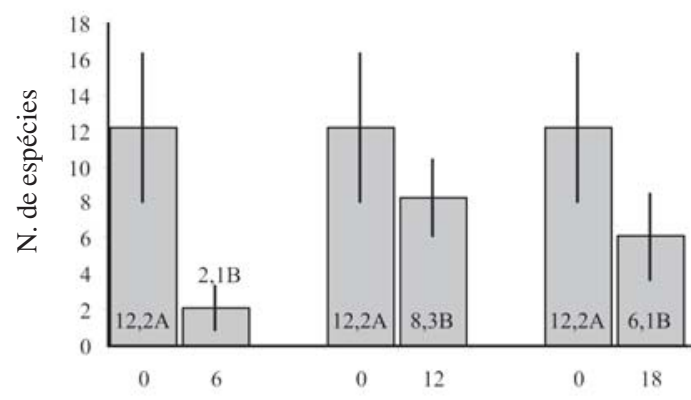

Tratamento II - interior do remanescente

(100\% retirada das plântulas sem revolvimento posterior do solo)

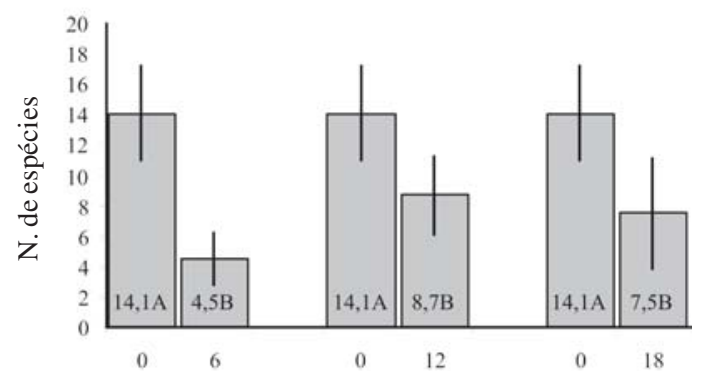

Tratamento $\mathrm{HI}-$ interior do remanescente (50\% retirada das plântulas sem revolvimento posterior do solo)

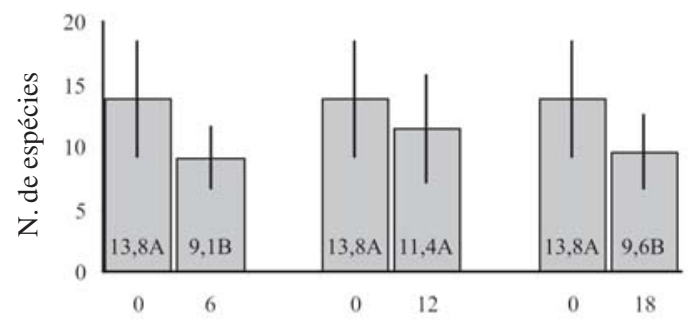

Tratamento IV - interior do remanescente (testemunha sem retirada de plântulas)

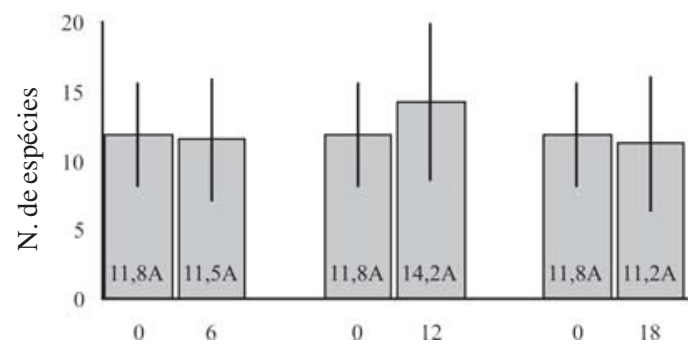

Tempo (em meses) após a retirada das plântulas

Figura 4. Comparação do número médio de espécies de plântulas arbustivas ou arbóreas por parcela ( $2 \times 2 \mathrm{~m})$, na avaliação prévia (tempo 0$)$ e aos 6, 12 e 18 meses após a aplicação dos tratamentos. Barras com letras diferentes diferem entre si $(\mathrm{P}<0,05)$. Linhas verticais em preto correspondem ao intervalo de confiança (95\%). Remanescente de Floresta Estacional Semidecidual, Fazenda Santa Terezinha, Bofete, SP, Brasil. 
submetidas a diferentes tratamentos de remoção de plântulas.

Sugere-se que a utilização de regenerantes de áreas naturais visando a produção de mudas para a restauração florestal, seja focada em espécies com alta densidade de regeneração e com raleamento intra-específico evidente, tal como observado em Protium spruceanum. Para espécies com baixa densidade, estudos sobre a dinâmica de regeneração das populações são essenciais para a compreensão do impacto específico da retirada dos regenerantes sobre a manutenção das espécies na comunidade.

\section{Agradecimentos}

À Coordenação de Aperfeiçoamento de Pessoal de Nível Superior (Capes), pela bolsa de estudos concedida ao primeiro autor e à Eucatex Florestal SA, pelo apoio e infra-estrutura disponibilizada.

\section{Referências bibliográficas}

Auer, C.G. \& Graça, M.C.E. 1995. Método de produção de mudas de canela-sassafrás a partir de mudas de regeneração natural. Boletim de Pesquisas Florestais 30/31: 75-77.

Barbosa, L.M.; Barbosa, J.M.; Barbosa, K.C.; Potomati, A.; Martins, S.E.; Asperti, L.M.; Melo, A.C.G.; Carrasco, P.G.; Castanheira, S.A.; Piliackas, J.M.; Contieri, W.A.; Mattioli, D.S.; Guedes, D.C.; Santos Júnior, N.; Silva, P.M.S. \& Plaza, A.P. 2003 Recuperação florestal com espécies nativas no Estado de São Paulo: pesquisas apontam mudanças necessárias. Florestar Estatístico 6: 28-34.

Box, G.E.P.; Hunter, W.G. \& Hunter, J.S. 1978. Statistics for experimenters: An introduction to design, data analysis, and model building. New York, John Wiley \& Sons, Inc.

Campos, H. 1983. Estatística experimental não-paramétrica. Piracicaba, Escola Superior de Agricultura "Luiz de Queiroz".

Carmo, M.R.B. \& Morellato, L.C.P. 2004. Fenologia de árvores e arbustos das matas ciliares da bacia do rio Tibagi, Estado do Paraná, Brasil. Pp. 125-141. In: R.R. Rodrigues \& H.F. Leitão Filho (eds.). Matas ciliares: conservação e recuperação. São Paulo, Edusp/Fapesp.

Clark, D.B. \& Clark, D.A. 1985. Seedling dynamics of a tropical tree: impacts of herbivory and meristem damage. Ecology 66: 1884-1892.

De Steven, D. 1994. Tropical tree seedling dynamics: recruitment patterns and their population consequences for three canopy species in Panama. Journal of Tropical Ecology 10: 385-398.

Denslow, J.S. 1991. The effect of understory palms and cyclanths on the growth and survival of Inga seedlings. Biotropica 23 225-234.

Di Bitetti, M.S.; Placci, G. \& Dietz, L.A. 2003. Uma visão de biodiversidade para a ecorregião Florestas do Alto Paraná - bioma Mata Atlântica: planejando a paisagem de conservação da biodiversidade e estabelecendo prioridades para ações de conservação. Washington, World Wildlife Fund.

Dinerstein, E.; Olson, D.M.; Graham, D.; Webster, A.; Primm, S.; Bookbinder, M. \& Ledec, G. 1995. A conservation assessment of the terrestrial ecoregions of Latin America and the Caribbean. Washington, The World Bank in association with The World Wildlife Fund.
Djers, G.; Hadengganan, S.; Kuusipalo, J.; Otsamo, A. \& Vesa, L. 1998. Production of planting stock from wildings of four Shorea species. New Forests 16: 185-197.

Fonseca, C.E.L.; Ribeiro, J.F.; Souza, C.C.; Rezende, R.P. \& Balbino, V.K. 2001. Recuperação da vegetação de matas de galeria: estudos de caso no Distrito Federal e entorno. Pp. 815-870. In: J.F. Ribeiro; C.E.L. Fonseca \& J.C. Souza e Silva (eds.). Caracterização e recuperação de matas de galeria. Planaltina, Embrapa-CPAC.

Grombone-Guaratini, M.T. \& Rodrigues, R.R. 2002. Seed bank and seed rain in a seasonal semi-deciduous forest in south-eastern Brazil. Journal of Tropical Ecology 18: 759-774.

Hubbell, S.P.; Foster, R.B.; O’Brien, S.T.; Harms, K.E.; Condit, B.; Weschsler, B.; Wright, S.J. \& Loo De Lao, S. 1999. Light-gap disturbance, recruitment limitation, and tree diversity in a Neotropical Forest. Science 283: 554-557.

Kwit, C.; Platt, W.J. \& Slater, H.H. 2000. Post hurricane regeneration of pioneer plant species in south Florida subtropical hardwood hammocks. Biotropica 32: 244-251

Laurance, W.F.; Ferreira, L.V.; Rankin-De Merona, J.M.; Laurance, S.G.; Hutchings, R.W. \& Lovejoy, T.E. 1998. Effects of forest fragmentation on recruitment patterns in Amazonian tree communities. Conservation Biology 12: 460-464.

Laurance, W.F.; Lovejoy, T.E.; Vasconcelos, H.L.; Bruna, E.M.; Didham, R.K.; Philip, C.S.; Gascon, C.; Bierregaard, R.O.; Laurance, S.G. \& Sampaio, E. 2002. Ecosystem Decay of Amazonian Forest Fragments: a 22-Year Investigation. Conservation Biology 16: 605-618.

Lieberman, D. 1996. Demography of tropical tree seedlings: a review. Pp. 131-138. In: M.D. Swaine (ed.). The ecology of tropical forest tree seedlings. Paris, UNESCO and Parthenon Publishing Group.

Melo, F.P.L.; Aguiar Neto, A.V.; Simabukuro, E.A. \& Tabarelli, M. 2004. Recrutamento e estabelecimento de plântulas. Pp. 237-250. In: A.G. Ferreira \& F. Borghetti (eds.). Germinação do básico ao aplicado. Porto Alegre, Artmed.

Morellato, L.C.P. 1995. As estações do ano na floresta. Pp. 37-41. In: L.C.P. Morellato \& H.F. Leitão Filho (eds.). Ecologia e preservação de uma floresta tropical urbana - reserva Santa Genebra. Campinas, Editora da Unicamp.

Murcia, C. 1995. Edges effects in fragmented forest: implications for conservation. Trends in Ecology and Evolution 10: 58-62.

Nemer, T.G.; Jardim, F.C.S. \& Serrão, D.R. 2002. Sobrevivência de mudas da regeneração natural de espécies arbóreas três meses após o plantio em clareiras de diferentes tamanhos, Moju-PA. Revista Árvore 26: 217-221.

Nunez-Farfan, J. \& Dirzo, R. 1988. Within-gap spatial heterogeneity and seedling performance in a Mexican tropical forest. Oikos 51: 274-84.

Oliveira, L.M.; Davide, A.C. \& Carvalho, M.L.M. 2003. Avaliação de métodos para quebra da dormência e para a desinfestação de sementes de canafístula (Peltophorum dubium (Sprengel) Taubert. Revista Árvore 27: 597-603.

Oliveira, R.J.; Mantovani, W. \& Melo, M.M.R.F. 2001. Estrutura do componente arbustivo-arbóreo da floresta atlântica de encosta, Peruíbe, SP. Acta Botanica Brasilica 15: 391-412.

Pimentel-Gomes, F. \& Garcia, C.R. 2002. Estatística aplicada a experimentos agronômicos e florestais: exposição com exemplos e orientações para uso de aplicativos. Piracicaba, FEALQ.

Putz, F.E. 1983. Treefall pits and mounds, buried seeds, and the importance of soil disturbance to pioneer trees on Barro Colorado Island, Panama. Ecology 64: 1069-1074.

Rozza, AF.; Farah, F.T. \& Rodrigues, R.R. 2007. Ecological management of degraded forest fragments. Pp. 171-196. In: R.R. Rodrigues; S.V. Martins \& S. Gandolfi (eds.). High Diversity Forest Restoration in Degraded Areas: Methods and Projects in Brazil. New York, Nova Science Publishers. 
1026 Viani \& Rodrigues: Impacto da remoção de plântulas sobre a estrutura da comunidade regenerante de Floresta...

Santarelli, E.G. 2004. Produção de mudas de espécies nativas. Pp. 313-318. In: R.R. Rodrigues \& H.F. Leitão Filho (eds.) Matas ciliares: conservação e recuperação. São Paulo, EDUSP/Fapesp.

Santos, S.L. \& Válio, I.F.M. 2002. Litter accumulation and its effect on seedling recruitment in a Southeast Brazilian Tropical Forest. Revista Brasileira de Botânica 25: 89-92.

Schupp, E.W.; Howe, H.F.; Augspurger, C.K. \& Levey, D.J. 1989. Arrival and survival in tropical treefall gaps. Ecology 70: 562-564.

SIGRH. 2007. Sistema de Informaç̃es para o Gerenciamento de Recursos Hídricos do Estado de São Paulo. Disponível em http://www.sigrh.sp.gov.br/cgi-bin/sigrh_index.exe, (Acesso em: 28/12/2007).

Silva, C.V.; Bilia, D.A.C.; Maluf, A.M. \& Barbedo, C.J. 2003. Fracionamento e germinação de sementes de uvaia (Eugenia pyriformis Cambess. - Myrtaceae). Revista Brasileira de Botânica 26: 213-221

Souza, F.M. \& Batista, J.F.L. 2004. Restoration of seasonal semideciduous forests in Brazil: influence of age and restoration design on forest structure. Forest Ecology and Management 191: $185-200$
Swaine, M.D. \& Whitmore, T.C. 1988. On the definition of ecological groups in tropical rain forests. Vegetatio 75: 81-86.

Vázques-Yanes, C. \& Orozco-Segovia, A. 1993. Patterns of seed longevity and germination in the tropical rainforest. Annual Review of Ecology and Systematics 24: 69-87.

Veloso, H.P. 1992. Manual técnico da vegetação brasileira. Rio de Janeiro, IBGE - Departamento de Recursos Naturais e Estudos Ambientais.

Viani, R.A.G.; Nave, A.G. \& Rodrigues, R.R. 2007. Transference of seedlings and aloctone young individuals as ecological restoration methodology. Pp. 145-170. In: R.R. Rodrigues; S.V. Martins \& S. Gandolfi (eds.). High diversity forest restoration in degraded areas: methods and projects in Brazil. New York, Nova Science Publishers.

Viani, R.A.G. \& Rodrigues, R.R. 2007. Sobrevivência em viveiro de mudas de espécies nativas retiradas da regeneração natural de remanescente florestal. Pesquisa Agropecuária Brasileira 42: 1067-1075.

Whitmore, T.C. 1989. Canopy gaps and the two major groups of forest trees. Ecology 70: 536-538.

Zamith, L.R. \& Scarano, F.R. 2004. Produção de mudas de espécies das Restingas do município do Rio de Janeiro, RJ, Brasil. Acta Botanica Brasilica 18: 161-176.

Versão eletrônica do artigo em www.scielo.br/abb e http://www.botanica.org.br/acta/ojs 